\title{
Research on Industrial Ecological System Based on Emergy Analysis Liming $\mathrm{Xia}^{1}$, Xu Zhang ${ }^{1, \mathrm{a}}$, Jianchao Yang $^{1}$ \\ ${ }^{1}$ Tianjin University of Technology School of Management, Tianjin 300384, China \\ a329277778@qq.com
}

Keywords: Industrial ecosystems, emergy analysis, sustainable development.

\begin{abstract}
The development and evolution of the industrial ecosystem, which is a valuable form of sustainable development strategy, became the concentration of government and scholar. However, with the continuous development of industrial ecosystem, many problems have been exposed, such as its structure, technology, and external environmental factors, and they've caused some negative impact on the sustainable evolution of IES. This paper will introduce the emergy analysis to study the process of evolution of IES, taking Tianjin Binhai New Area for example, and aims to provide a theoretical basis and development strategy for the sustainable evolution of Tianjin Binhai New Area ecosystem.
\end{abstract}

\section{Introduction}

With the continuous development and innovation of science and technology, the productivity has been greatly improved, and economy has never been more robust. However, along with economic growth is huge consumption and low utilization efficiency of resources. Industrial ecologists present an eco-industrial system that is similar to the circular economy mode of the natural ecological system. China has been vigorously promoting the construction of the IES, and now has achieved preliminary results. Therefore, with the continuous development of industrial ecosystem, many problems have emerged such as lack of system stability, imperfect of industrial chain construction and reduction of the utilization rate of recycled waste, causing negative impact on the sustainable evolution of IES. In view of the above questions, based on emergy theory, this paper selects the appropriate indicators to build the evaluation system, studies the relationship between environmental stress and sustainable development of Tianjin Binhai New Area, and aims to provide theoretical basis and strategy for the future construction.

\section{Theory and method}

\section{Emergy Theory.}

Emergy theory was established by the famous ecologist H.T.Odum, and it develops a new method for quantitative analysis of the ecosystem. The emergy definition by Odum is the quantity of the emergy in other form which is contained in a flow or stored emergy[1], that is, the total quantity of emergy put in to create goods and services is the emergy it possesses[2].In application, solar emergy to value is used as a benchmark, and the unit of emergy is solar emjoule(sej).

Emergy analysis converts the flow and stored emergy or material in IES into emergy by a objective standard, and easy for quantitative analysis[2]. In recent years, emergy analysis is widely used, ranging from the natural ecological system to the social economic system and industrial, agricultural system. Some scholars studied the degree of sustainable development of environmental carrying capacity and resource utilization in China, Italy and Peru[3-5], some scholars analyzed and evaluated the sustainability of urban ecosystem[6-7],and there are also some scholars using the emergy theory to analyze the agriculture system, wetland system, nature reserve and industrial system[8-10].However, the emergy theory applied in the ecosystem of high-tech industrial development zone is still at a stage of early exploration[11].

\section{Emergy Flow Chart.}

Determine the system boundary, emergy source and main components; list the relations and process of each component in the IES, and draw the emergy flow chart, as shown in Fig.1. 


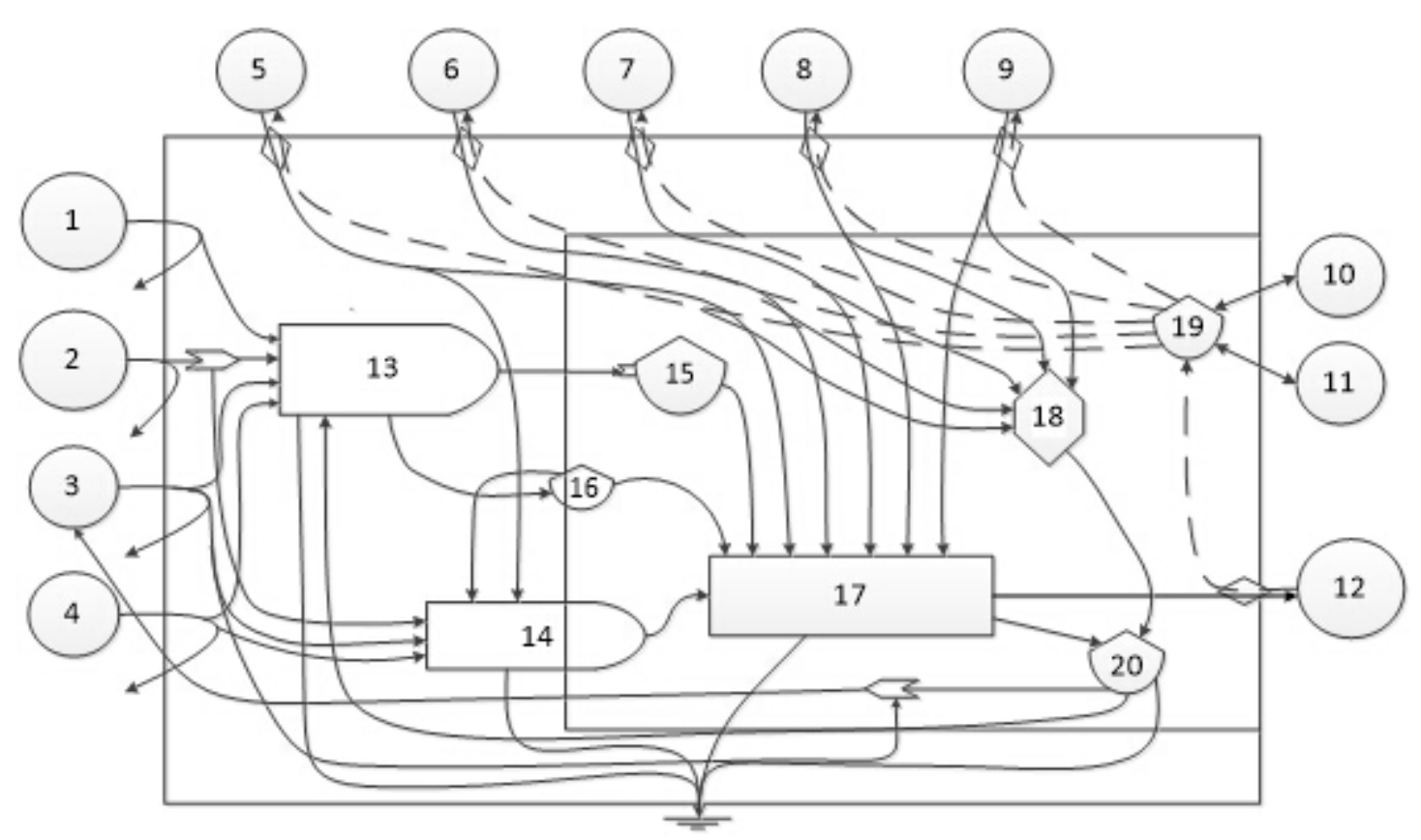

Fig.1 Eco-economic System Emergy Analysis Diagram in Tianjin Binhai New Area Symbol implication: 1-rotation of the earth; 2-chemical emergy and potential emergy of rain; 3-wind emergy; 4-solar emergy; 5-water and electric;6-fuel; 7- equipment; 8-technical information 9-labour services; 10-foreign investment; 11-offshore fund; 12-market; 13-natural ecosystem 14-green space; 15-soil; 16-water; 17-industrial park; 18-community; 19-currency; 20-waste

\section{Indices.}

(1)Emergy Self-sufficiency Ratio, ESR

ESR is a ratio between nature input emergy $(R+N)$ and total emergy (U). It can be used to describe the degree of the development and foreign exchange of the region.

(2) Environmental Load Ratio, ELR

ELR is a ratio between non renewable resource emergy (U-R) and renewable emergy $(R)$. It can evaluate the system operation impact to environment.

(3) Emergy Exchange Ratio, EER

EER is an exchange rate between input and output emergy, it embodies the exchange efficiency. The higher it is ,the more powerful its trading position is.

(4) Emergy Yield Ratio, EYR

EYR compares exported emergy $(\mathrm{R}+\mathrm{N}+\mathrm{I})$ with input emergy (I), which quantifies the effectiveness of system output to economy.

(5) Environmental Sustainability Index, ESI

ESI is calculated as the ratio of EYR to ELR, which measures the production of a system relative to the environmental pressure

(6) Emergy Indices for Sustainable Development, EISD

EISD is a complex sustainable index based on ESI which considers EER (EYR*EER/ELR).The higher it is, the better the economic benefits and sustainability of IES are.

\section{Case Study}

The research region, Tianjin Binhai New Area, is on the verge of Bohai, about 2270 square kilometer. Its geographical coordinate is $38^{\circ} 40^{\prime} \mathrm{N}-39^{\circ} 00^{\prime} \mathrm{N}, 117^{\circ} 20^{\prime} \mathrm{E}-118^{\circ} 00^{\prime} \mathrm{E}$. Its geographical position is superior, and it is in the core position of Bohai economic circle, as the biggest artificial harbor, the most potential market in China. The GDP of Tianjin Binhai New Area reached 620.69 billion yuan in 2011, and it has been at the forefront of similar area in China.

The basic data in this paper comes from Tianjin statistical yearbook, China emergy statistics yearbook,etc. 


\section{Results.}

Tab.1Emergy Evaluation Indices of Eco-economic System in Tianjin Binhai New Area

\begin{tabular}{|c|c|c|c|c|c|c|}
\hline \multirow{2}{*}{ Classfication } & \multirow{2}{*}{ emergy Indices } & \multicolumn{5}{|c|}{ Year } \\
\hline & & 2007 & 2008 & 2009 & 2010 & 2011 \\
\hline \multirow{7}{*}{$\begin{array}{l}\text { emergy } \\
\text { flow }\end{array}$} & Renewable emergy & $4.08 \mathrm{E}+21$ & $4.05 \mathrm{E}+21$ & $4.06 \mathrm{E}+21$ & $4.07 \mathrm{E}+21$ & $4.07 \mathrm{E}+21$ \\
\hline & Unrenewable emergy & $2.12 E+23$ & $2.24 \mathrm{E}+23$ & $2.39 E+23$ & $2.78 E+23$ & $2.96 E+23$ \\
\hline & Input emergy & $6.27 \mathrm{E}+22$ & $9.30 \mathrm{E}+22$ & $1.12 \mathrm{E}+23$ & $1.12 \mathrm{E}+23$ & $1.26 \mathrm{E}+23$ \\
\hline & Output emergy & $3.58 \mathrm{E}+22$ & $3.81 \mathrm{E}+22$ & $2.88 \mathrm{E}+22$ & $3.40 \mathrm{E}+22$ & $4.04 \mathrm{E}+22$ \\
\hline & labour services emergy & $1.83 E+22$ & $1.97 \mathrm{E}+22$ & $2.32 \mathrm{E}+22$ & $3.05 E+22$ & $4.81 \mathrm{E}+22$ \\
\hline & emergy of waste & $4.04 \mathrm{E}+22$ & $3.97 \mathrm{E}+22$ & $4.31 \mathrm{E}+22$ & $5.48 \mathrm{E}+22$ & $3.98 \mathrm{E}+22$ \\
\hline & Total emergy & $2.61 E+23$ & $3.03 E+23$ & $3.49 \mathrm{E}+23$ & $3.91 E+23$ & $4.34 \mathrm{E}+23$ \\
\hline \multirow{5}{*}{ Nature subsystem } & ESR & 0.8270 & 0.7535 & 0.6955 & 0.7222 & 0.6918 \\
\hline & Ratio of input emergy & 0.2400 & 0.3073 & 0.3205 & 0.2868 & 0.2905 \\
\hline & ELR & 63.04 & 73.73 & 85.07 & 94.96 & 105.58 \\
\hline & emergy investment rate & 67.33 & 78.27 & 86.45 & 95.82 & 103.69 \\
\hline & Ratio of waste emergy & 0.1546 & 0.1312 & 0.1233 & 0.1403 & 0.0918 \\
\hline \multirow{3}{*}{$\begin{array}{l}\text { Economic } \\
\text { subsystem }\end{array}$} & Electric emergy per capita & $8.71 \mathrm{E}+16$ & $7.44 \mathrm{E}+16$ & $6.99 \mathrm{E}+16$ & $8.02 \mathrm{E}+16$ & $8.59 \mathrm{E}+16$ \\
\hline & EER & 1.7514 & 2.4409 & 3.8889 & 3.2941 & 3.1188 \\
\hline & EYR & 4.4463 & 3.4522 & 3.1702 & 3.5185 & 3.3815 \\
\hline \multirow{2}{*}{ Social subsystem } & emergy per capita & $1.52 \mathrm{E}+17$ & $1.49 \mathrm{E}+17$ & $1.52 \mathrm{E}+17$ & $1.57 \mathrm{E}+17$ & $1.71 \mathrm{E}+17$ \\
\hline & Density of emergy & $1.15 \mathrm{E}+14$ & $1.33 \mathrm{E}+14$ & $1.54 \mathrm{E}+14$ & $1.72 \mathrm{E}+14$ & $1.91 \mathrm{E}+14$ \\
\hline \multirow{2}{*}{$\begin{array}{c}\text { System } \\
\text { sustainable indices }\end{array}$} & ESI & 0.0705 & 0.0468 & 0.0373 & 0.0371 & 0.0320 \\
\hline & EISD & 0.1235 & 0.1143 & 0.1449 & 0.1221 & 0.0999 \\
\hline
\end{tabular}

\section{Discussion.}

From 2007 to 2011, nonrenewable resource emergy increased by 1.67 times and increased by 2.01 times,implying that the rapid economic development of Tianjin Binhai New Area is mainly driven by external emergy input and the consumption of nonrenewable resources. ESR of the New Area decreased during 5 years, which implies the local resources have been unable to meet the needs, and the IES is more dependent on outside world. In addition, ELR continued to grow and it means the development of the New Area brings great pressure on the environment, making ecosystem overloaded. EER had been in a rising state, reaching above 1 as it implies.

\section{Reference}

[1]H.T.Odum.EcologyandEconomy:“Emergy”AnalysisandPublicPolicyinTexas[M].Texas:TheOffic eofNationalResourcesandTexasDepartmentofAgriculture,1987: 163-171. 
[2]Shengfang Lan, Pei Qin, Hongfang Lu.emergy Analysis ofEcological economic system[M].Beijing: Chemical industry press, 2002.

[3] ZF.Yang, M.M. Jiang, B.Chen. Solar emergy Evaluation forChinese Economy[J]. Emergy Policy, 2010(2):875-886

[4] S.Ulgiati, H.T.Odum, S.Bastianoni. emergy Use, Environ-mental Loading and Sustainability An emergy Analysis of Italy[J]. Ecological Modelling, 1994(3-4):215-268

[5]Raúl Siche, Lucas Pereira, Feni Agostinbo. Convergence of Eco-logical Footprint and emergy Analysis as A Sustainability Indica-tor of Countries: Peru as Case Study[J].Commun Nonlinear SciNumer Simulat, 2010(10): 3182-3192

[6]Daniel E, Campbell, Ahjond S, Garmestani. An Emergy SystemsView of Sustainability: emergy Evaluation of the San Luis Basin, Colorado[J].Journal of Environmental Management, 2012(1):72-97

[7]Yan Zhang, Zhifeng Yang, Xiangyi Yu. Evaluation of Urban Me-tabolism Based on emergy Synthesis: A Case Study for Beijing(China)[J]. Ecological Modelling,2009(13):1690-1696

[8] J.B.Zhou, M.M.Jiang, B.Chen, G.Q.Chen. emergy Evalu-ations for Constructed Wetland and Conventional WastewaterTreatments[J]. Communications in Nonlinear Science and Numerical Simulation,2009(4):1781-1789

[9]Julie Brothe Higgins. emergy Analysis of the Oak Openings R egion[J].Ecological Engineering, 2003(1):75-109

[10] Mark T. Brown, Marco Raugei, Sergio Ulgiati. On Boundariesand”Investments”in emergy Synthesis and LCA: A Case Study on Thermal VS. Photovoltaic Electricity[J].Ecological Indicators,2012(1):227-235

[11]Yong Geng, Pan Zhang, Sergio Ulgiati, Joseph Sarkis. emergy Analysis of An Industrial Park: The Case of Dalian, China[J].Science of the Total Environment,2010(22):5273-5283 